\title{
CARACTERIZAÇÃO DE OBSTÁCULOS EPISTEMOLÓGICOS NA CONCEPÇÃO DE LICENCIANDOS EM QUÍMICA QUE DIFICULTAM O DESENVOLVIMENTO DO CONHECIMENTO PROFISSIONAL DOCENTE
}

\author{
Graziele B. O. Penaa e Nyuara A. S. Mesquita ${ }^{\mathrm{b}, *}$ \\ anstituto de Ciências Exatas e da Terra, Universidade Federal de Mato Grosso, Campus Universitário do Araguaia, 78698-000 \\ Pontal do Araguaia - MT, Brasil \\ 'Instituto de Química, Universidade Federal de Goiás, Campus Samambaia, 74690-900 Goiânia - GO, Brasil
}

Recebido em 22/12/2017; aceito em 11/04/2018; publicado na web em 09/05/2018

\begin{abstract}
CHARACTERIZATION OF EPISTEMOLOGICAL OBSTACLES IN THE CONCEPTION OF STUDENTS OF CHEMISTRY THAT HAMPER THE DEVELOPMENT OF TEACHING PROFESSIONAL KNOWLEDGE. The change in the way of teaching Chemistry requires, among others aspects, the rupture of established teaching practices and involves the professional development of teachers. Several conditions are necessary for such changes to take place, such as the recognition and legitimation of a specific knowledge to teach Chemistry as the Pedagogical Knowledge of Chemistry Content (PCKC) and the identification and characterization of obstacles that hamper the development of this professional knowledge. In this context, this article aims to describe the characterization of two epistemological obstacles: valorative obstacle and experiential obstacle, identified in the concept of undergraduate students of Chemistry Degree. The identification of obstacles of an epistemological nature in the concept of future Chemistry teachers can contribute to the improvement of the teacher training, since it gives subsidies to promote the learning of professional knowledge in Chemistry and perhaps to strengthen the professionalization of this career.
\end{abstract}

Keywords: chemistry teaching; teaching epistemological obstacles; valorative obstacle; experiential obstacle, Pedagogical Knowledge of Chemistry Content.

\section{INTRODUÇÃO}

A relação entre ciência, sociedade e tecnologia ${ }^{1}$ pode ser compreendida como um dos aspectos que justificam a necessidade dos indivíduos se apropriarem de conhecimentos que lhes tornem capazes de tomarem decisões de forma consciente e crítica. Diante da mudança de comportamento que a sociedade tem vivenciado nos últimos anos, é necessária a compreensão de que não podemos ensinar química como essa era ensinada em décadas passadas. ${ }^{2,3}$ De acordo com os documentos orientadores da educação nacional e com as atuais tendências explicitadas por pesquisadores da área de Ensino de Química, os conhecimentos químicos têm o importante papel no processo de alfabetização científica. ${ }^{4,5}$ Nesse sentido, Sasseron e Carvalho ${ }^{6}$ explicitam que o termo alfabetização científica designa as ideias de:

[...] um ensino que permita aos alunos interagir com uma nova cultura, com uma nova forma de ver o mundo e seus acontecimentos, podendo modificá-los e a si próprio através da prática consciente propiciada por sua interação cerceada de saberes de noções e conhecimentos científicos, bem como das habilidades associadas ao fazer científico. (p.61)

Nessa perspectiva, as propostas curriculares destacam que a Química, ${ }^{7}$

[...] pode ser um instrumento da formação humana que amplia os horizontes culturais e a autonomia no exercício da cidadania, se o conhecimento químico for promovido como um dos meios de interpretar o mundo e intervir na realidade, se for apresentado como ciência, com seus conceitos, métodos e linguagens próprios, e como construção histórica, relacionada

*e-mail: nyuara@ufg.br ao desenvolvimento tecnológico e aos muitos aspectos da vida em sociedade. (p.87)

Chassot $^{8}$ salienta que um dos questionamentos que usualmente se faz ao ensino é a respeito de sua quase inutilidade na construção de uma cidadania mais crítica e afirma que: "[...] se os estudantes não tivessem, por exemplo, durante três anos a disciplina de Química no ensino médio eles não seriam muito diferentes no entender os fenômenos químicos. Nosso ensino é literalmente (in)útil [...]” (p.41).

Segundo Maldaner, ${ }^{9}$ a mudança na forma de ensinar Química é demasiado complexa e, para tal, necessita-se de uma mudança de paradigma e de ruptura de práticas já instauradas, "[...] a ruptura do círculo vicioso em que se encontra o atual programa de ensino de Química não é uma tarefa tão simples" (p.221). Mellado, ${ }^{10}$ ao argumentar sobre a complexidade do processo de mudança e desenvolvimento profissional de professores de ciências, afirma que são necessárias muitas condições para fazer alterações e indica a existência de obstáculos que dificultam ou impossibilitam os professores de mudar suas concepções e modelos didáticos. Compreende-se que a mudança na forma de ensinar depende do professor e de seu desenvolvimento profissional e está implicada neste processo a superação de obstáculos. Desta forma, se faz necessário compreender melhor quais obstáculos impedem a mudança de paradigma e de modelo didático por professores de Química, bem como a melhoria do desenvolvimento do conhecimento profissional docente. Neste viés é que se estrutura o objetivo desta pesquisa, que visa caracterizar obstáculos epistemológicos na concepção de licenciandos em Química que dificultam o desenvolvimento do conhecimento profissional específico para a docência em Química, que adotamos como Conhecimento Pedagógico do Conteúdo de Química (CPCQ) ${ }^{11} \mathrm{O}$ universo de estudo relaciona-se a licenciandos de Química em fase de conclusão da formação inicial matriculados no último estágio supervisionado do curso de Licenciatura em Química da Universidade Federal de Mato Grosso do Campus Universitário do Araguaia. 
A identificação de obstáculos de natureza epistemológica na concepção de futuros professores de Química pode colaborar com reflexões sobre questões formativas uma vez que subsidia discussões que podem promover a aprendizagem do conhecimento profissional docente em Química e quiçá fortalecer a profissionalização dessa carreira.

\section{Conhecimento profissional docente: caminhos para profissionalização e melhoria da formação de professores.}

A formação inicial e a prática pedagógica do professor têm sido responsabilizadas pelos problemas apontados no processo de ensino-aprendizagem dos estudantes da educação básica, como atentam os autores Costa et al..$^{12}$ Entretanto, essa responsabilização evidencia o desconhecimento dos vários fatores que envolvem esse complexo processo. Gatti ${ }^{13}$ menciona alguns desses fatores:

[...] políticas educacionais postas em ação, o financiamento da educação básica, aspectos das culturas nacional, regionais e locais, hábitos estruturados, [...] a condição do professorado: sua formação inicial e continuada, os planos de carreira e salário dos docentes da educação básica, as condições de trabalho nas escolas. (p. 1359)

Segundo Marcelo, ${ }^{14}$ a formação de professores e a melhoria da educação são processos indissolúveis. Deste modo, mudanças no processo de ensino-aprendizagem só serão alcançadas se houver o reconhecimento de que este processo é imbricado e que não ocorrerá com esforços pueris aplicados em um ou em outro fator de forma isolada. As melhorias da formação inicial docente e da prática do professor dependem de diferentes fatores, dentre eles, a consolidação da profissionalização da docência. De acordo com Montero ${ }^{15}$

O conceito de profissionalização abraça ambos os níveis e procura elevar o ensino a uma ocupação mais respeitada, responsável e melhor recompensada. Os defensores da profissionalização escoram os seus argumentos na disponibilidade de um corpus de conhecimento fundamentado para o ensino. (p. 198)

O processo de profissionalização da docência tem contribuído, nas últimas décadas, para a legitimação deste grupo profissional. Entretanto, segundo Nóvoa, ${ }^{16}$ "a afirmação profissional dos professores é um percurso repleto de lutas e de conflitos, de hesitações e de recuos" (p. 21). A profissionalização da docência é uma temática complexa, pois envolve várias questões, como a proletarização - perda de controle da totalidade do seu trabalho, questões de jornada de trabalho, condições e divisões de trabalho, remuneração, autonomia e saberes profissionais e a constituição de um código deontológico para a profissão. ${ }^{17}$ Roldão, ${ }^{18}$ sem desconsiderar outros elementos, afirma que a centralidade do conhecimento profissional é um fator decisivo da distinção profissional. Compreender que para a atuação docente é necessário haver um corpo de conhecimento profissional específico pode colaborar para a desconstrução de concepções simplistas sobre o fazer docente e, consequentemente, valorizar e incentivar a profissionalização do professor.

$\mathrm{O}$ estudo de Montero ${ }^{15}$ colabora para o entendimento do processo histórico de produção do conhecimento profissional docente, abordando dentre outras linhas de estudo as de Lee Shulman. O Conhecimento Pedagógico do Conteúdo (CPC ou PCK da expressão em inglês Pedagogical Content Knowledge) proposto por Shulman ${ }^{19,20}$ é o conceito que mais tem contribuído para a definição do conhecimento profissional docente que distingue o professor do especialista.
Maldaner ${ }^{21}$ defende que deve haver um conhecimento específico para a formação do educador químico:

Esse novo conhecimento precisa circular, ser recriado nas instâncias de formação de educadores químicos, ser valorizado no contexto social amplo e específico da produção dos fatos químicos. É, portanto, um conhecimento que vai além de dar boas aulas de Química. (p.270)

Vários estudos e debates têm sido realizados para melhorar o entendimento do PCK em diversas áreas, inclusive estudos e propostas de modelos de PCK para a área de ensino de ciências e Química. ${ }^{22-25}$ Há ainda estudos que se dedicam à utilização e análise do PCK na formação específica de professores de Química. ${ }^{29-31,21}$

Pena e Mesquita, ${ }^{11}$ a partir da análise dos trabalhos de Shulman e de trabalhos relacionados com o PCK propõem a denominação e definição de um PCK específico para a docência em Química

[...] que seria o Conhecimento Pedagógico do Conteúdo de Química $(C P C Q)$ - Pedagogy Content Knowledge Chemistry $(P C K C)$ - o conhecimento específico que distingue o educador Químico do especialista, construído ativamente pelo professor na ação e pela ação reflexiva, por um processo complexo de transformação das categorias de conhecimento da base atual de conhecimento, via processo baseado no Modelo de Raciocínio Pedagógico da Ação (MRPA) de Lee Shulman. (p.6)

A base de conhecimento, segundo Pena e Mesquita ${ }^{11}$ seria composta pelos seguintes conhecimentos: Conhecimento do Conteúdo, Conhecimento Pedagógico, Conhecimento Curricular, Conhecimento dos Alunos, Conhecimento dos Contextos, Conhecimento dos Fins e Conhecimento Pedagógico do Conteúdo Tecnológico.

Discussões que permitem a definição de um conhecimento específico para a docência em Química são importantes para valorizar e fortalecer a formação e a carreira docente. Entretanto, mesmo que os conhecimentos profissionais para a docência em Química sejam clarificados, compreendidos e que façam parte do currículo de formação de professores, não podemos deixar de considerar a pouca influência da formação inicial de professores para o exercício da docência. Mellado, ${ }^{29}$ em seu estudo, verificou que as concepções de professores de ciência são pouco alteradas pela formação universitária. Tardif e Raymond ${ }^{30}$ também afirmam que crenças adquiridas na formação ambiental dificilmente são desconstruídas pela formação inicial.

Na América do Norte, percebe-se que a maioria dos dispositivos de formação inicial dos professores não consegue mudá-los nem abalá-los. Os alunos passam através da formação inicial para o magistério sem modificar substancialmente suas crenças anteriores sobre o ensino. (p. 217)

Neste contexto, as experiências e crenças adquiridas durante a formação ambiental dificultam a formação de professores no que tange à aprendizagem de conhecimentos específicos para o exercício da docência e colaboram para que a formação docente tenha um papel secundário sobre o pensamento e a prática dos professores. Ao pensar em uma necessária ruptura do conhecimento adquirido pela formação ambiental, conhecimento este que contribui para obstacularizar a compreensão e desenvolvimento do conhecimento profissional, percebemos relações possíveis com a epistemologia bachelardiana, especialmente, com o conceito de obstáculo epistemológico, que pode contribuir para melhorar a compreensão sobre o processo formativo 
para a docência em Química, tendo em vista uma formação menos pautada em conhecimentos de senso comum do fazer docente.

\section{A epistemologia bachelardiana e o conceito de obstáculos epistemológicos}

Epistemólogo francês, Gaston Bachelard viveu entre 1884 a 1962 e vivenciou um período de grandes revoluções na ciência, notadamente da Física Relativística e da Mecânica Quântica. ${ }^{31}$ Bachelard contribuiu especialmente no campo da história da ciência com críticas ao pensamento comum para o desenvolvimento da ciência contemporânea e com a ideia de espírito científico, teceu ainda críticas ao "realismo ingênuo, ao empirismo e ao racionalismo cartesiano que permeiam os discursos e as práticas científicas" ${ }^{\prime 32}$ (p.312). Um dos conceitos da epistemologia bachelardiana refere-se a obstáculo epistemológico, descrito por ele em 1938, que o define da seguinte maneira: ${ }^{33}$

[...] é no âmago do próprio ato de conhecer que aparecem, por uma espécie de imperativo funcional, lentidões e conflitos. É aí que mostraremos causas de estagnação e até de regressão, detectaremos causas de inércia às quais daremos o nome de obstáculos epistemológicos. (p.17)

O epistemólogo discute vários tipos de obstáculos epistemológicos, tais como: opinião, experiência primeira, conhecimento geral, verbal, conhecimento unitário e pragmático, substancialista, animista dentre outros. ${ }^{33}$ Segundo Bachelard ${ }^{33} \mathrm{o}$ ato de conhecer se dá contra um conhecimento anterior eliminando conhecimentos mal estabelecidos e este afirma que "um obstáculo epistemológico se incrusta no conhecimento não questionado" (p.19). A ruptura com o conhecimento de senso comum e a compreensão do processo de construção do conhecimento científico seria possível, segundo Bachelard, à medida que os obstáculos epistemológicos fossem superados. A noção de obstáculo epistemológico segundo Bachelard pode ser estudada no desenvolvimento histórico do pensamento científico e também na prática da educação, conforme explicita Lopes: ${ }^{32}$

No campo da Educação, a análise dos obstáculos epistemológicos contribui para que se suplante o que Bachelard (1947) denomina de obstáculo pedagógico: entraves que impedem o aluno de compreender o conhecimento científico. A aprendizagem de um novo conhecimento é um processo de mudança de cultura, sendo necessário, para tal, que suplantemos os obstáculos epistemológicos existentes nos conhecimentos prévios do aluno. Torna-se necessária uma catarse intelectual e afetiva, capaz de psicanalisar o conhecimento objetivo do educando e, por que não dizer?, de todos nós, professores. (p.316)

Bachelard diz se sentir surpreendido que os professores de ciências, mais até que outros professores, não compreendam que alguém não compreenda. Segundo o epistemólogo francês a aprendizagem de uma cultura científica depende de uma psicanálise dos erros iniciais dos alunos: $:^{33}$

[...] toda cultura científica deve começar por uma catarse intelectual e afetiva. Resta, então, a tarefa mais difícil: colocar a cultura científica em estado de mobilização permanente, substituir o saber fechado e estático por um conhecimento aberto e dinâmico, dialetizar todas as variáveis experimentais, oferecer enfim à razão razões para evoluir. Tais razões podem, aliás, ser generalizadas: são mais visíveis no ensino de ciências, mas aplicam-se a qualquer esforço educativo. (p.24)
Pesquisas sobre obstáculos epistemológicos que dificultam a aprendizagem dos conhecimentos da ciência Química por alunos foram realizadas por Lopes. ${ }^{31,32,34,35}$ Baseando-se no conceito de obstáculo epistemológico de Bachelard aplicado para contextos de sala de aula, Brosseau apresenta a perspectiva de obstáculo didático e argumenta que este se configuraria pela falta de domínio dos conceitos fundamentais de matemática pelo professor e, como consequência, causaria dificuldade de aprendizagem dos alunos. De acordo com Gomes: ${ }^{36}$

Brosseau (1983) aponta que estes obstáculos didáticos se manifestam através de erros que são reprodutíveis, persistentes. Estes erros estão ligados entre si por uma fonte comum: uma maneira de conhecer, uma concepção característica, coerente, se não correto, um conhecimento antigo e que obteve êxito em todo domínio de ação. Erros que não são facilmente explícitos e não podem desaparecer radicalmente, de uma forma instantânea. Persistem num momento, ressurgem em outros, manifestam-se muito tempo depois do sujeito ter rejeitado o modelo defeituoso de seu sistema cognitivo. (p.372)

Estudos como os de Brosseau colaboraram para a aplicação da epistemologia bachelardiana no campo da didática e no contexto da formação de professores. Porlán et al. ${ }^{37}$ mencionam que os obstáculos de natureza espistemológica de Bachelard foram utilizados por diferentes autores que transferiram o conceito para o campo da didática das ciências e ampliaram seu significado. Em suas pesquisas, Porlán e colaboradores aplicam o conceito de obstáculo epistemológico para o caso dos professores relacionado ao processo de desenvolvimento do conhecimento profissional docente..$^{37-39}$

[...] partimos da hipótese que uma parte importante das concepções e das atuações dos professores refletem uma determinada visão epistemológica e que esta visão tem um papel importante de estruturador, bloqueando ou dinamizando, fragmentando ou integrando, parcelas importantes de seu conhecimento profissional. ${ }^{38}$ (p. 161)

Mellado ${ }^{10}$ se baseia em uma analogia com a mudança científica na filosofia da ciência para analisar os processos de mudança de concepções e práticas educativas de professores de ciências. Bachelard, sobre as razões necessárias à psicanálise da razão e consequentemente aprendizagem de uma cultura científica, afirma que elas não se aplicam somente ao ensino de ciências, podem também ser generalizadas a qualquer esforço educativo e menciona essa generalização no caso de professores.

O educador não tem o senso do fracasso justamente porque se acha um mestre. Quem ensina manda. Daí a torrente de instintos [...]. Educador e educando merecem uma psicanálise especial. [...] De maneira mais precisa, detectar os obstáculos epistemológicos é um passo para fundamentar os rudimentos da psicanálise da razão. ${ }^{33}$ (p.24). [grifo nosso].

Bachelard destaca a importância de detectar obstáculos epistemológicos para o caso dos professores, no que diz respeito à possível mudança de método pedagógico. Nesse sentido adotamos em nossa pesquisa a perspectiva bachelardiana de obstáculo epistemológico aplicada ao caso dos professores de Química para identificar obstáculos epistemológicos na concepção de futuros professores de Química relacionados com dificuldades para o desenvolvimento pelo professor de seu conhecimento profissional docente, o Conhecimento Pedagógico do Conteúdo de Química - CPCQ. A partir 
do conhecimento desses obstáculos poderemos discutir caminhos para melhoria da formação acadêmica do professor de Química e quiçá dar subsídios para mudanças das práticas docentes relacionadas ao processo de ensino e aprendizagem que se pautem em modelos didáticos mais atuais de ensino dessa ciência.

\section{CAMINHOS METODOLÓGICOS}

Para identificar obstáculos epistemológicos nas concepções de futuros professores de Química acerca do conhecimento profissional docente entendemos ser necessário compreender o conhecimento objetivo do educando para retirar dele seu caráter subjetivo, pois só aí poderíamos identificar obstáculos incrustados no conhecimento prévio dos sujeitos de pesquisa. A metodologia adotada por essa pesquisa se caracteriza pela investigação qualitativa. Segundo Bodgan e Biklen (1982 apud Lüdke e André) ${ }^{40}$ a pesquisa qualitativa:

envolve a obtenção de dados descritivos, obtidos no contato direto do pesquisa com a situação estudada, enfatiza mais o processo do que o produto e se preocupa em retratar a perspectiva dos participantes. (p. 13)

Já a análise de dados foi realizada segundo os pressupostos da Análise Textual Discursiva (ATD) proposta por Moraes e Galiazzi. ${ }^{41}$

A análise textual discursiva pode ser entendida como o processo de descontrução, seguido de reconstrução, de um conjunto de materiais linguísticos e discursivos, produzido-se a partir disso novos entendimentos sobre os fênomenos e discursos investigados. Envolve identificar e isolar enunciados dos materiais submetidos à análise, categorizar esses enunciados e produzir textos, integrando nestes descrição e interpretação, utilizando como base de sua construção o sistema de categorias construído. (p.112)

A análise textual discursiva num ciclo de análise que se contitui de três elementos: unitarização, categorização e comunicação, possibilita um movimento do qual emergem novas compreensões com base na auto-organização. ${ }^{42}$

A decisão de investigar a concepção de licenciandos em Química que estivessem por concluir a graduação foi baseada na premissa de que poderíamos verificar a concepção deles em relação ao conhecimento profissional docente sem grandes influências do processo de socialização que ocorre no início da carreira docente, já que nesta fase da docência ocorrem várias mudanças de concepções. ${ }^{43}$

O projeto de pesquisa foi submetido ao Comitê de Ética da Universidade Federal de Goiás e, após parecer favorável, iniciamos a coleta de dados que ocorreu durante um semestre e se deu pela aplicação de instrumentos de coleta de dados (questionário e entrevista) e pelo acompanhamento das aulas (observação participante) da última disciplina de estágio supervionado do curso de Licenciatura em Química da Universidade Federal de Mato Grosso, Campus Universitário do Araguaia. Todos os alunos da disciplina concordaram em participar da pesquisa, totalizando um universo de dezesseis participantes que realizaram estágios em diferentes escolas e em duplas. Os Termos de Livre Consentimento foram assinados por todos os participantes e as identidades deles serão mantidas em sigilo. Cada sujeito de pesquisa recebeu um código de identificação que se inicia pelas letras "SP" cujo o significado é "Sujeito de Pesquisa" e é seguido por um número que varia de 01 a 16 de acordo com o número de cada participante da pesquisa. $\mathrm{O}$ acompanhamento presencial se deu apenas nos encontros de estágio realizados pela professora da disciplina no campus da universidade, que totalizaram oito encontros de quatro horas cada, ou seja, os participantes da pesquisa não foram acompanhados durante a realização do estágio nas escolas. Além desse acompanhamento na forma de observação participante, foi aplicado um questionário de dez questões no início do semestre, respondido por quatorze sujeitos de pesquisa (dois faltaram no dia em que o questionário foi aplicado) e o outro instrumento de coleta de dados aplicado, foram as entrevistas com característica de microgrupofocal. Os sujeitos de pesquisa foram entrevistados tanto individualmente, quanto em dupla e em trio, seguindo o mesmo padrão de divisão das equipes que realizaram o estágio. As entrevistas foram realizadas quase no final do semestre e tiveram em média de 15 a 50 min e foram concedidas por um total de treze participantes. A observação participante constituiu um instrumento para orientação da análise do questionário e da entrevista, uma vez que, possibilita conhecer melhor os sujeitos de pesquisa. Dessa forma, suas contribuições são menos visíveis, mas, não menos importantes do que aquelas advindas dos outros instrumentos metodológicos utilizados nessa pesquisa. As perguntas do questionário foram elaboradas com foco no conhecimento profissional específico para a docência em Química (Conhecimento Pedagógico do Conteúdo de Química - CPCQ) e com os sete conhecimentos da base de ensino de Química mencionados anteriormente. A entrevista também teve como objetivo investigar as concepções dos sujeitos de pesquisa com o mesmo foco, entretanto, foi realizada após os sujeitos de pesquisa terem concluído a regência do estágio.

\section{Metodologia de análise dos dados}

Segundo Moraes e Galiazzi, ${ }^{41}$ a primeira etapa da ATD denominada unitarização consiste na desconstrução/fragmentação dos dados em unidades de análise com aspectos específicos definidos coerentemente com o objetivo da pesquisa e do objeto de investigação. Conforme os autores, "unitarizar um conjunto de textos é identificar e salientar enunciados que os compõem” (p.114). Na primeira etapa da análise foram realizadas desmontagens dos textos das respostas do questionário para cada sujeito de pesquisa e das entrevistas. Nesse processo de desmontagem dos textos, foram identificadas as unidades de sentido relacionadas com os conhecimentos da base de ensino de Química e o CPCQ conforme representado na Tabela 1. Importante ressaltar que essas unidades de sentido emergiram em estreita relação com a perspectiva teórica que conduz o olhar do pesquisador e que, na investigação em questão, relaciona-se aos conhecimentos de Shulman que sustentam a construção de uma nova perspectiva de conhecimentos necessários ao professor de química. Moraes $^{42}$ afirma que:

É importante que o pesquisador proceda a suas análises de modo que saiba em cada momento quais as unidades de contexto, geralmente os documentos, que deram origem a cada unidade de análise. Para isso utilizam-se códigos que indicam a origem de cada unidade. (p.195)

Deste modo, para a codificação dos dados foi atribuído uma letra correspondente aos instrumentos de coleta de dados como: "Q" para questionário e "E" para entrevista. Para a codificação das unidades de sentido advindas do questionário adicionamos um número que corresponde a cada questão, seguida por um símbolo de underline mais o código de identificação do sujeito de pesquisa que respondeu a questão. Assim o código Q04_SP14 indica que a unidade de sentido está no material advindo do questionário, questão quatro respondida pelo sujeito de pesquisa identificado pelo número quatorze.

Depois as unidades de sentido advindas do questionário foram justapostas com as unidades de sentido advindas da entrevista e em seguida iniciamos a próxima etapa da ATD denominada de 
Tabela 1. Unitarização das respostas do questionário e das transcrições das entrevistas conforme as unidades de sentido

\begin{tabular}{|c|c|}
\hline & Unidades de Sentido \\
\hline \multirow{7}{*}{ 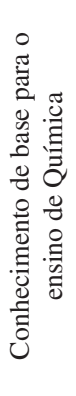 } & Conhecimento dos Alunos em relação aos conteúdos químicos \\
\hline & Conhecimento dos Fins Educacionais do ensino de química \\
\hline & Conhecimento Tecnológico relacionado ao ensino de química \\
\hline & Conhecimento do Conteúdo de química \\
\hline & Conhecimento Pedagógico Geral com foco nas aulas de química \\
\hline & $\begin{array}{l}\text { Conhecimento Curricular considerando os entrelaces da química } \\
\text { com o currículo escolar }\end{array}$ \\
\hline & $\begin{array}{l}\text { Conhecimento do Contexto escolar considerando os aspectos do } \\
\text { ensino de química }\end{array}$ \\
\hline
\end{tabular}

Conhecimento Pedagógico do conteúdo de Química (CPCQ)

categorização, que implica a busca em "[...] construir relações entre as unidades de base, combinando-as e classificando-as no sentido de compreender como esses elementos unitários podem ser reunidos na formação de conjuntos mais complexos, as categorias" "42 (p 191). $\mathrm{O}$ processo de categorização foi de natureza indutiva e subjetiva, ou seja, esse processo produz categorias emergentes. Importante ressaltar que, embora a perspectiva da existência dos obstáculos possa ser considerada a priori, a emergência destes explicitados em suas características como categorias, deu-se a posteriori a partir da imersão nos dados. Um exemplo da forma de entrelace das unidades no processo de construção das categorias pode ser identificado na Figura 1.

A partir do processo de categorização emergiram os obstáculos epistemológicos que buscávamos caracterizar e que foram denominados: Obstáculo Valorativo e Obstáculo Experencial. Ambas as categorias foram concebidas pela união das unidades de sentido relacionadas com o conhecimento profissional específico para a docência em Química e com o conhecimento do conteúdo e, a partir delas, pudemos nos aproximar da concepção dos participantes da pesquisa e entender como essas concepções podem obstacularizar o desenvolvimento do conhecimento profissional para a docência em Química. Uma observação importante que fazemos é que toda essa problemática relacionada a aspectos que entravam a apropriação dos saberes docentes específicos da formação de professores de química já estão postos na literatura, ${ }^{2,3,8,11}$ mas o que propomos nessa pesquisa é uma compreensão para essas questões em termos de obstáculos epistemológicos, pois entendemos que há um conhecimento vinculado à formação do professor de Química que é construído no processo formativo sendo este conhecimento de natureza específica: o CPCQ.

\section{RESULTADOS E DISCUSSÃO}

Ao estabelecermos relações entre as unidades de sentido no processo de categorização, cunhamos alguns termos com vistas à promoção da discussão sobre os obstáculos epistemológicos presentes na concepção de licenciandos de Química que dificultam o desenvolvimento e a compreensão do Conhecimento Pedagógico do Conteúdo de Química (CPCQ). A seguir são apresentadas as discussões referentes ao processo investigativo.

\section{Obstáculos epistemológicos ao desenvolvimento do conhecimento profissional do professor de Química - CPCQ}

\section{Obstáculo Valorativo}

Ao investigarmos as unidades de sentido relacionadas ao conhecimento profissional específico para a docência em Química nos aproximamos de algumas concepções dos sujeitos de pesquisa que puderam demonstrar a relevância do conhecimento do conteúdo. $\mathrm{Na}$ questão oito os sujeitos de pesquisa foram questionados sobre quais conhecimentos que os professores de Química deveriam ter para ensinar, observe o gráfico (Figura 2) que representa as repostas.

Dos respondentes da questão oito (treze do total de participantes), nove deles mencionaram que o conhecimento necessário para o professor de Química ensinar seria o conhecimento do conteúdo o que corresponde a um valor aproximado de $69 \%$ das respostas dos sujeitos de pesquisa (SP_10; SP_01; SP_09; SP_15; SP_05; SP_03; SP_04; SP_06; SP_13). Analisando as respostas que constituem esse valor de 69\%, 77\% (SP10; SP01; SP09; SP03; SP04; SP06; SP13) delas indicaram que o conhecimento necessário para o professor seria apenas aquele relacionado como conhecimento do conteúdo. Esse valor indica não só uma supervalorização do conhecimento do conteúdo, mas também a falta do reconhecimento da existência de outros saberes necessários para o exercício da docência. Ainda analisando as respostas que se enquadram dentro dos 69\%, duas delas, dadas pelos participantes SP_10 e SP_09, afirmam que, o professor deveria: "saber tudo de química" e "saber todos os conceitos de Química e de outras áreas do conhecimento relacionadas com a Química,

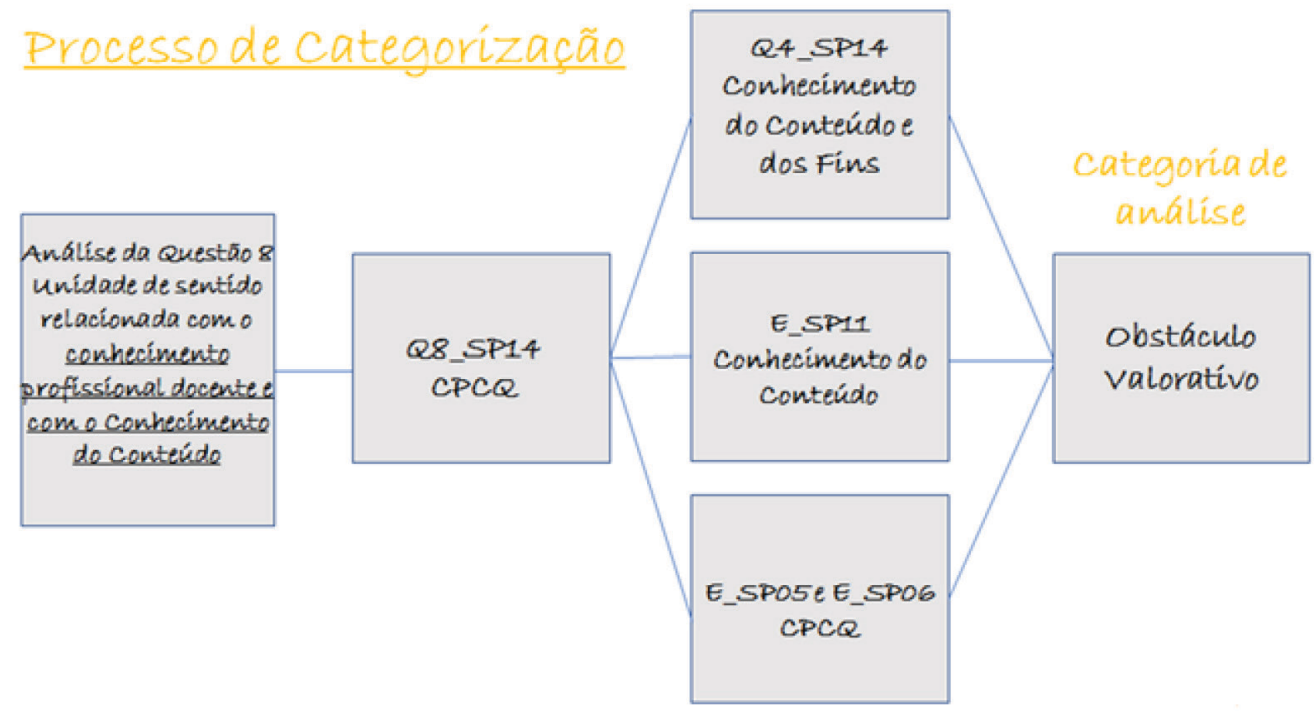

Figura 1. Exemplo do processo de construção das categorias de análise 


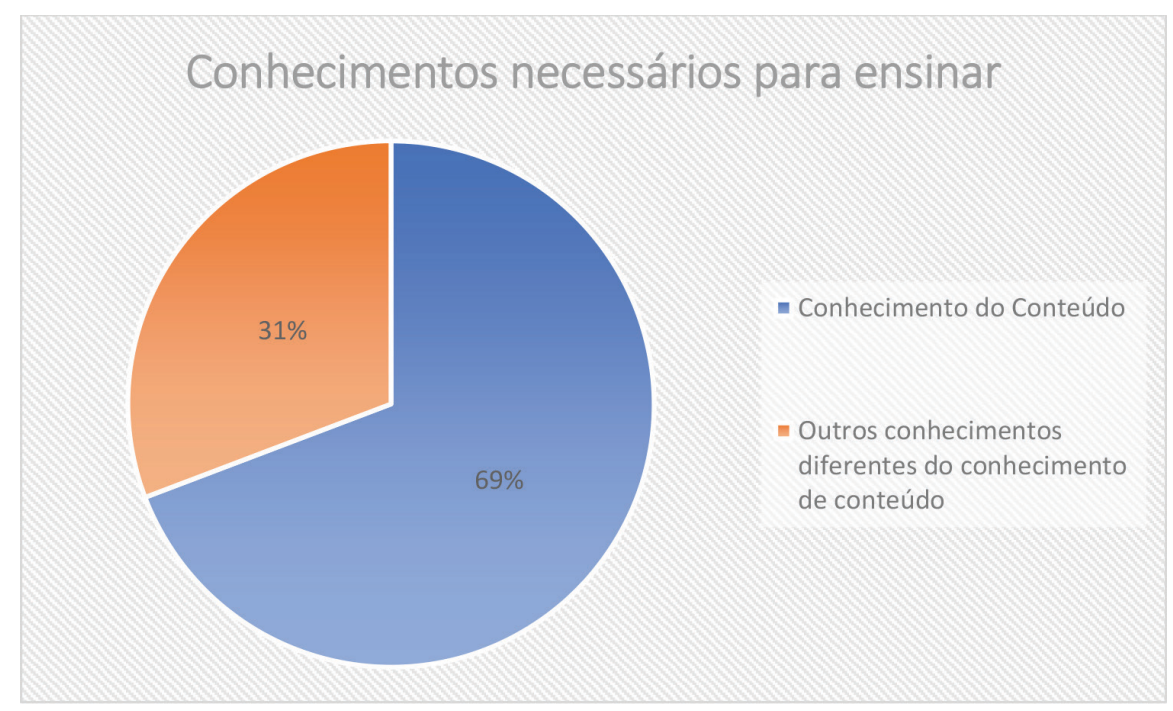

Figura 2. Respostas da questão oito do questionário investigativo aplicado

como a Biologia, Física e Matemática, dentre outras". Nota-se uma concepção empirista de conhecimento, uma vez que, nesse tipo de epistemologia, o conhecimento está pronto e finalizado. Talvez, por esse motivo, os sujeitos de pesquisa considerem possível saber tudo de Química ou de outras ciências. Já as respostas de SP06 e SP13 mencionam que, o professor de Química deve ter conhecimento do conteúdo em um nível geral.

Nas respostas que correspondem a $31 \%$, não foi mencionado pelos sujeitos de pesquisa SP12, SP07, SP11 e SP14 que o conhecimento do conteúdo é um dos conhecimentos necessários ao professor de Química. Dado este, alarmante, uma vez que esses participantes não mencionam a necessidade do conhecimento do conteúdo de Química para ensinar Química. Shulman ${ }^{19}$ identificou essa falta de atenção com o conteúdo específico e denominou-o de paradigma perdido e segundo ele era necessário melhorar o reconhecimento da importância do conhecimento de conteúdo para a formação e atuação do professor. Analisando as quatro respostas que constituem esse valor de $31 \%$, uma menciona a necessidade do professor ser licenciado em Química (SP07), saber dar aula (SP12), conhecer sua própria identidade como docente (SP11) e uma resposta que indica não reconhecer o saber do professor como conhecimento, observe a resposta na íntegra:

Q8_SP14: Na verdade não trato conhecimento mais sim uma formação que prepara da melhor maneira possivel a fim de que o professor seja didático, inovador e o principal querer ser professor e não simplesmente ser por falta de opção. [grifo nosso]

A dificuldade em reconhecer o conhecimento profissional docente é uma das consequências do obstáculo epistemológico que denominamos de obstáculo valorativo, que seria um obstáculo relacionado com a supervalorização do conhecimento do conteúdo e que constituem um obstáculo à compreensão da existência do conhecimento profissional docente, ou seja, há valoração maior, por parte dos licenciandos, para o conhecimento de conteúdo químico. O aprofundamento da investigação desse obstáculo valorativo pode ser evidenciado pela fala de SP14 ao responder a quarta questão do questionário a qual foi questionado "O que significa para você dizer que os alunos aprenderam Química?"

Q04_SP14: Aprender química é um processo longo a ser desenvolvido e trabalhado no ensino fundamental e médio e vejo esse aprendizado significativo como base para o cidadão e sua formação. Agora aprender química a fundo é um sistema complexo que demanda a fixação e aprendizado de conceitos. [grifo nosso]

A resposta é composta por duas frases que evidenciam uma "dualidade" de significados acerca do "aprender química", ou seja, apresenta concepções distintas e contraditórias sobre a aprendizagem química que é mais evidendente pelo modo como a segunda frase é iniciada: "Agora aprender Química a fundo [...]”. Percebemos dois tipos de concepção de aprendizagem Química para SP14 um tipo mais "a fundo" e que demanda fixação e aprendizagem de conceitos e outro tipo que demanda tempo e que serve de base para a formação do cidadão. Devido à contradição presente na frase, compreendemos que a concepção de aprendizagem relacionada com a formação do cidadão é entendida como sendo mais "superficial" e menos relacionada com a aprendizagem conceitual. A concepção do sujeito acerca da aprendizagem Química exposta na segunda frase denota uma visão tradicional de ensinar Química, enquanto que na primeira frase, devido ao uso de alguns termos, como "aprendizado significativo", há uma concepção menos tradicional e mais coerente com modelos didáticos alternativos. Além disso, essa aprendizagem, segundo SP14, demanda desenvolvimento (pelo professor) e tempo, o que poderia indicar compreensão do fazer docente segundo modelos didáticos alternativos, ou seja, demanda "certo trabalho" do professor e não somente transmitir conteúdos. Cruzando esses dados com a análise da fala de SP11 durante parte da entrevista, percebemos também evidências de dois tipos de concepção de aprendizagens química. SP11 menciona que no estágio utilizou a metodologia de projetos considerada por ele um método de ensino diferenciado do tradicional. Sobre a aprendizagem desse método afirmou:

E_SP11: Vale mais o aprendizado do aluno do que o ensino tradicional. Mesmo que absorver menos.

Percebemos na fala a existência de uma dualidade conceitual de aprendizagem e uma atribuição distinta de valores para esse termo. Considerando o contexto da fala e o recorte acima, percebemos que SP11 atribui ao aprendizado advindo da aplicação de modelos alternativos ao tradicional um maior valor, entretanto, esse valor estaria associado a aprendizagens úteis para a vida em sociedade com um menor valor em termos conceituais. SP11 indica que o ensino tradicional não produz aprendizagens com valor para a vida em sociedade, mas a aprendizagem advinda deste modelo é considerada mais "eficiente" para aprendizagens conceituais. Ou seja, dependendo do modelo didático aplicado, tem-se aprendizagens distintas e de valores diferentes. Ao mencionar que o aluno "absorve menos" quando o modelo didático aplicado não é o tradicional, o sujeito dá indícios de uma concepção de aprendizagem ancorada no modelo didático tradicional, no qual a ênfase do conhecimento tem um valor em si mesmo e é: ${ }^{44}$ 
[...] estruturado de forma linear e transmitido pelo professor ao aluno. Como o ensino se dá por transmissão, a aprendizagem é considerada uma acumulação ou absorção desse conhecimento que existe pronto e acabado no exterior do sujeito que aprende. (p.15). [grifo nosso]

Ao mencionar o termo "absorve", fica evidente que SP11 compreende que o tipo de aprendizagem obtida pela aplicação do modelo didático tradicional é de certo modo eficiente em proporcionar aprendizagens no nível conceitual, mesmo que este modelo não produza "certo tipo" de aprendizagem que "vale" mais para a vivência em sociedade.

Durante a entrevista realizada com a dupla SP05 e SP06 foi mencionado que uma das alunas da classe que realizaram estágio possuía problemas psicológicos e não sabia ler. Quando foram indagados pela pesquisadora sobre como lidar com estudantes com alguma dificuldade como essa aluna do estágio, SP05 respondeu:

E_SP05: Aí você tem que fazer uma adaptação para ele voltada, para o cotidiano, para que ele entenda.

Quanto ao perfil de alunos que possuem reconhecidamente limitações e mais dificuldade de aprendizagem, SP05 menciona que para que ocorram aprendizagens desses alunos há a necessidade de adaptação e associação com o cotidiano, pois assim os alunos com dificuldade de aprendizagem poderiam entender. A proposição da "adaptação voltada para o cotidiano" para o ensino de Química para aluno que possui reconhecida dificuldade de aprendizagem, conforme SP05 afirma, corrobora a tese de que este tipo de ensino para alguns professores é desprovido de dificuldade porque se ensina "menos conteúdo" ou seja, é um conhecimento com menor valor em grau de aprendizagem de Química em nível conceitual.

Pela análise realizada percebemos que há uma concepção de supervalorização do conhecimento do conteúdo dos participantes da pesquisa o que nos leva a definir esta concepção como um obstáculo de natureza epistemológica, que denominaremos de obstáculo valorativo, o qual impede a compreensão e o desenvolvimento do conhecimento profissional específico para a docência em Química (CPCQ), pois:

- dificulta a compreensão do conhecimento profissional específico para a docência em Química, como por exemplo o CPCQ, porque compreende o conhecimento do conteúdo como sendo o próprio conhecimento profissional docente;

- gera dificuldade de compreensão de que o conhecimento profissional específico para a docência em Química é constituído por uma justaposição de outros conhecimentos e não só pelo conhecimento do conteúdo;

- dificulta a compreensão de que a transformação do conhecimento de conteúdo necessária para produzir o conhecimento profissional específico para a docência não o "deforma", devido à concepção que o ensino desse conhecimento transformado produziria uma aprendizagem de menor valor em termos conceituais.

Dessa forma, a concepção de supervalorização do conhecimento do conteúdo obstaculariza o desenvolvimento do conhecimento profissional específico para a docência em Química (CPCQ), e por isso constitui o obstáculo valorativo.

\section{Obstáculo Experencial}

Bachelard ${ }^{33}$ afirma que para a formação do espírito científico o primeiro obstáculo é a experiência primeira, pois:

Um obstáculo epistemológico se incrusta no conhecimento não questionado. Hábitos intelectuais que foram úteis e sadios podem, com o tempo, entravar a pesquisa. [...] Com o uso, as idéias se valorizam indevidamente. Um valor em si opõe-se à circulação dos valores. É fator de inércia para o espírito. Às vezes, uma idéia dominante polariza todo o espírito [...]. (p. 19)

A experiência vivida na condição de aluno, sem uma devida reflexão, propicia a internalização de ideias e crenças que, muitas vezes, pode dificultar o desenvolvimento profissional docente. Dessa forma, a identificação de obstáculos de natureza epistemológica na concepção de licenciandos de Química, contribui para constituir um conhecimento importante e necessário para melhorar o entendimento do processo de formação do professor de Química, especialmente, no que tange à constituição de um saber pautado em um conhecimento profissional docente especializado como o conhecimento pedagógico do conteúdo de Química (CPCQ) e promover uma superação do conhecimento de senso comum do fazer docente em Química. Importante salientarmos que há elementos formativos nos cursos de licenciatura que poderiam contribuir com a superação da perspectiva simplista que os licenciandos têm da docência.

Dentre esses elementos, citam-se as Práticas como Componente Curricular (PPC). Embora sejam 400 horas que devem contemplar aspectos específicos da relação teoria e prática para o exercício da docência, na prática, ainda há muitas lacunas em termos de implementação dessa carga horária, bem como falhas que entravam um melhor aproveitamento dessas horas. Uma dessas lacunas tem relação com o perfil do professor formador para atuar na concretização das propostas de formação do educador químico para a Educação Básica. De acordo com Maldaner, ${ }^{21}$ há carência desse profissional nas diversas instituições. No caso específico da instituição onde se desenvolveu a pesquisa, no período em que a investigação aconteceu, havia apenas dois docentes com formação na área de Ensino de Química em atuação no curso. Isso posto, reafirmam-se as dificuldades em mudar concepções adquiridas na experiência vivida dos estudantes em relação ao ser professor.

Porlán et al. ${ }^{37}$ citam vários trabalhos que indicam que as concepções dos alunos [futuros professores] interiorizadas a partir da experiência como aluno impedem/dificultam a mudança do ensino de ciência. Ao contrário de outras profissões, o professor tem a oportunidade de conhecer bem e durante muito tempo o local onde irá trabalhar, devido ao seu tempo de permanência na escola, na condição de aluno.

Os professores têm ideias, atitudes e comportamentos sobre o ensino, devido a um longo treinamento 'ambiental' durante o período quando eram estudantes. A influência deste treinamento incidental é enorme porque responde a experiências repetidas e adquiriu forma não-reflexiva, óbvio, "senso comum" natural, escapando assim a crítica e se tornando um obstáculo real (Gil, 1991, p. 73 apud Mellado, ${ }^{10}$ p. 22). [tradução nossa]

Em decorrência dessa vivência contínua com o ambiente de sala de aula e de percepções do exercício da docência constituídas durante o período em que foram estudantes, denominado de formação ambiental, as crenças adquiridas dificilmente são desconstruídas. ${ }^{9}$ Montero $^{15}$ afirma que a experiência que todos temos como alunos faz deste ofício uma profissão familiar e que essa aproximação torna a atividade docente desprovida de mistério em relação ao fazer de outras profissões.

A partir dessa experiência, é muito frequente dar-se por adquirido que todos sabemos o que um professor é e faz e, de algum modo, pré-julgamos e questionamos o seu saber. É óbvio que estas peculiaridades do ensino podem atuar como 
obstáculos epistemológicos tanto para a construção de conhecimento como para o reconhecimento do saber profissional de professores e professoras. (p.09) [grifo nosso]

A concepção de senso comum do fazer docente é uma antiga e problemática marca na formação docente em Química ${ }^{45}$ segundo a qual bastaria ao professor ter apenas um "bom conhecimento da matéria, algo de prática e alguns complementos pedagógicos” (p.14). Essa concepção de senso comum do fazer docente em Química é identificada na concepção dos sujeitos de pesquisa investigados na análise da questão cinco (Tabela 2). Nessa questão, solicitou-se que os licenciandos definissem o bom professor de Química. As características mais mencionadas por eles foram: domínio do conteúdo; saber transmitir os conteúdos/conceitos e/ou ter didática; associação de conceitos com cotidiano/dia-a-dia dos alunos; modelo real de professor e domínio de turma/sala. O quadro abaixo indica as cinco características mais mencionadas, seguida dos sujeitos que as mencionaram.

Tabela 2. Representa as características que definem o bom professor de Química indicada pela porcentagem e número de sujeitos que a mencionaram na questão 5 do questionário aplicado

\begin{tabular}{|c|c|}
\hline $\begin{array}{l}\text { Características mencionadas nas } \\
\text { respostas da questão cinco }\end{array}$ & $\begin{array}{l}\text { Sujeitos de pesquisa que } \\
\text { mencionaram }\end{array}$ \\
\hline domínio de conteúdo & $\begin{array}{c}9 \text { (SP15, SP05, SP08, SP11, SP04, } \\
\text { SP06, SP10, SP01, SP03) }\end{array}$ \\
\hline $\begin{array}{l}\text { saber transmitir os conteúdos/ } \\
\text { conceitos e/ou ter didática }\end{array}$ & $\begin{array}{l}8 \text { (SP01, SP08, SP07, SP11, SP15, } \\
\text { SP05, SP03, SP04) }\end{array}$ \\
\hline $\begin{array}{l}\text { associação de conceitos com o } \\
\text { cotidiano/dia-a-dia dos alunos }\end{array}$ & $\begin{array}{c}8 \text { (SP14, SP13, SP06, SP05, SP08, } \\
\text { SP12, SP09, SP10) }\end{array}$ \\
\hline modelo real de professor & 3 (SP10, SP01 e SP09) \\
\hline domínio de turma/sala & $2(\mathrm{SP} 01$ e SP3) \\
\hline
\end{tabular}

Outras nove características também foram mencionadas nas respostas, entretanto, apenas uma vez cada, deste modo não foram incluídas na Tabela 2. A seguir são indicadas essas características: "conhecimento dos alunos" mencionada por SP04; "fazer com que os alunos participem da aula" mencionada por SP13; "cativar" os alunos mencionada por SP10; "saber usar analogias (macro-micro)" mencionada por SP14; "aulas diversificadas" mencionada por SP13; "prepara aula" mencionado por SP01; "privilegiam com aulas ótimas" mencionado por SP09; "ter conhecimento do objetivo (saber o que quer)" mencionado por SP01; "ser licenciado" considerado como item primordial por SP05.

Sobre as características que definem o bom professor de Química, Talanquer ${ }^{25}$ menciona, dentre outras, a capacidade de transformação pedagógica do conhecimento científico e o reconhecimento da complexidade do processo de ensino-aprendizagem. Essas são características importantes, mas que não foram mencionadas pelos sujeitos que participaram de nossa pesquisa. A característica mais mencionada quando supervalorizada constitui o obstáculo valorativo que já foi mencionado, a segunda característica "saber transmitir os conceitos/ conteúdos e ter didática" é compreendida como uma concepção do tipo empirista na qual entende-se que a aprendizagem ocorre pela transferência do saber do professor para o aluno. A concepção transmissiva de ensino foi identificada por Porlán et al. ${ }^{30}$ como obstáculo epistemológico de mesmo nome na concepção de professores de ciência, além de identificarem outros obstáculos epistemológicos tais como: a aprendizagem por incorporação de significados externos que ignoram a existência de ideias espontâneas dos alunos e o absolutismo epistemológico no qual a mudança do ensino de ciências é dificultada pela concepção de ciência de professores que se baseia no empirismo e que compreende a ciência como produto pronto e acabado, superior, verdadeiro e incontestável.

As três primeiras características mais mencionadas indicam a concepção que os sujeitos de nossa pesquisa possuem do conhecimento profissional específico para a docência em Química, ou seja, concebem que o conhecimento para ensinar Química seja constituído primeiramente pelo domínio do conteúdo do professor, que o transmite aos alunos de forma associada ao cotidiano/dia-a-dia dos alunos. Essa concepção de conhecimento profissional para ensinar Química advinda da experiência não refletida de aluno dificulta a aprendizagem e o desenvolvimento de um conhecimento profissional pautado em um concepção diferente da empirista. Segundo Becker, ${ }^{46}$ a epistemologia que valoriza as relações hierárquicas de transmissão do conhecimento e que se fundamenta na epistemologia empirista constitui a epistemologia subjacente ao professor, e afirma que a concepção epistemológica:

[...] uma vez constituída, adquire um poder de determinação. Deste modo, um docente que professe uma epistemologia empirista não consegue, em função de sua concepção epistemológica, avançar pedagogicamente. Os avanços pedagógicos implicam mudanças de paradigma epistemológico. (p. 334)

Um obstáculo epistemológico na concepção de conhecimento profissional docente dificulta avanços pedagógicos na formação de professores, porque sem a superação deste obstáculo, dificilmente o futuro professor de Química terá condições de realizar mudanças de modelos didáticos, pois segundo o estudo de Pórlan e Riuver, 1998 apud Mellado, ${ }^{10}$ o conhecimento profissional não se desenvolve na concepção de modelo didático tradicional.

A Figura 3 representa a ideia de um quadro evolutivo para a formação de professores que parte de modelos didáticos tradicionais, passa por níveis intermediários até modelos alternativos mais inovadores, condicionada pela superação de obstáculos. Becker ${ }^{46}$

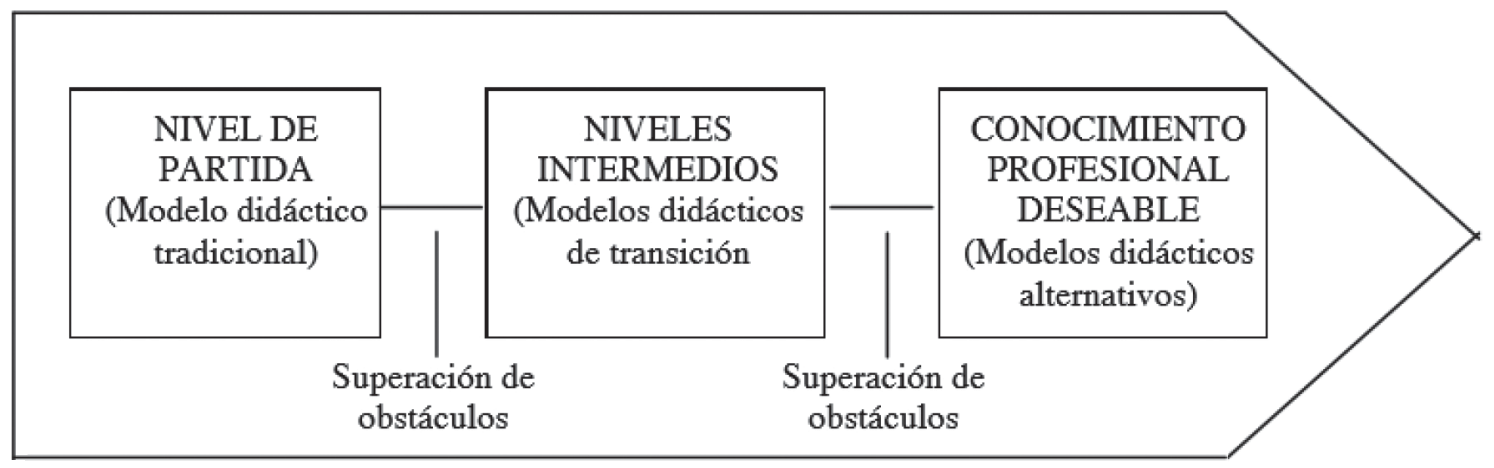

Figura 3. Processo de reorganização contínua do conhecimento profissional. Fonte: Pórlan e Riuver, 1998 apud Mellado ${ }^{10}$ (p. 25) 
afirma que a "epistemologia empirista constitui em larga escala e de forma quase totalmente insconsciente, o fundamento "teórico-filosófico" da pedagogia de repetição e de reprodução" (p.334). Ao solicitar aos sujeitos de pesquisa uma definição do bom professor de Química, questão cinco do questionário investigativo, três respostas apresentaram características em comum. Observe:

Q5_SP10: Professor " $x$ ” que é professor da disciplina Química "w” da UFMT. "Ótimos”. Saber o conteúdo, saber dar uma ótima aula contextualizada, cativar os alunos com seu jeito de dar aula.

Q5_SP01: $O$ “ “". É ter o domínio do conteúdo, preparar aula, saber o que quer e ter uma boa didática bem como domínio de sala.

Q5_SP09: Alguns professores da UFMT, como o professor " $x$ ", “ $y$ ” e o professor " $z$ ". São professores que nos privilegiam com aulas ótimas, associando os conceitos ao seu dia-a-dia.

A definição do bom professor de Química para SP10, SP01 e SP09 é pautada pela associação com modelos reais de professores que tiveram na graduação ("x", "y" e "z") e nas características deles para ensinar e se relacionar com os alunos. Tal associação mencionada pode ser evidência que os sujeitos de pesquisa se "espelham" nesses professores para definir e desenvolver suas práticas, baseando-se nas características que eles possuem.

De certo modo, isso pode constituir limitações e obstáculos para o desenvolvimento do conhecimento profissional docente. Em primeiro lugar, o "espelhar" pode levar a uma limitação da compreensão do papel ativo do professor na produção de seu conhecimento profissional, ou seja, o futuro professor, durante a sua graduação, pode enfrentar dificuldades para compreender que o conhecimento profissional específico é desenvolvido/construído pelo professor e não imitado/pronto. As características de um bom professor de Química quando atribuídas a um modelo real de professor, podem dificultar o entendimento que o conhecimento do professor é um conhecimento historicamente e socialmente construído pelas ciências e não um conhecimento que está no professor. Atribuir características de um bom professor de Química às características de um determinado professor, limita a compreensão do processo dinâmico de construção do conhecimento do professor. Pode ser adotada nesse contexto, uma postura empirista do licenciando frente ao conhecimento profissional especializado do professor e, dificilmente, o futuro professor adotará uma perspectiva ativa, construtiva e crítica do conhecimento profissional do professor de Química. Quando a experiência como aluno não é refletida de forma crítica e apoiada no conhecimento científico em construção sobre o conhecimento do professor, haverá dificuldades para que o conhecimento de senso comum do fazer docente em Química seja ser superado. Segundo Bachelard: ${ }^{26}$

Na formação do espírito científico, o primeiro obstáculo é a experiência primeira, a experiência colocada antes e acima da crítica - crítica esta que é, necessariamente, elemento integrante do espírito científico. Já que a crítica não pôde intervir de modo explícito, a experiência primeira não constitui, de forma alguma, uma base segura. (p. 29)

Deste modo a pedagogia a qual estivemos submetidos, que é predominantemente empirista por um processo de reprodução, constitui-se como a epistemologia subjacente ${ }^{46}$ ao trabalho docente e dela incorporamos certo tipo de conhecimentos que quando não refletidos e suplantados constitui o obstáculo experencial que impede que o conhecimento profissional específico para a docência, como por exemplo o Conhecimento Pedagógico do Conteúdo de Química (CPCQ) seja desenvolvido. Como afirma Bachelard, ${ }^{26}$ uma crença em um saber defninitivo pode dificultar mudanças pois:

Chega o momento em que o espiríto prefere o que confirma seu saber àquilo que o contradiz, em que gosta mais de res- postas do que de perguntas. O instinto conservativo passa então a dominar, e cessa o crescimento espiritual. (p. 19)

A incorporação de conhecimentos de senso comum ao longo da vivência não questionada como aluno constitui o obstáculo denominado experencial, pois dificulta que o professor compreenda a complexidade do processo de ensino e aprendizagem de modelos didáticos que não o tradicional impossibilitando o desenvolvimento do conhecimento profissional docente em Química (CPCQ).

\section{CONCLUSÃO}

A elucidação de obstáculos epistemológicos na concepção de futuros professores de Química colabora para a compreensão dos possíveis impedimentos ocorridos no processo de formação docente e no desenvolvimento do conhecimento profissional docente. Esse entendimento é importante para auxiliar na ruptura do ciclo vicioso da forma como a Química é ensinada, que tem predominantemente se baseado na concepção de senso comum do fazer docente e utilizado de práticas que pouco tem contribuído para a formação Química desejada para o século atual, especialmente no que tange a alfabetização científica. Assim como na epistemologia bachelardiana não há possibilidades de um continuísmo da concepção do senso comum para o desenvolvimento do conhecimento científico, não há um continuísmo do saber de senso comum para o desenvolvimento do professor que se paute em conhecimentos profissionais legitimidados. Deste modo, a relação entre a concepção de senso comum do fazer docente e o conhecimento profissional específico para a docência em Química são antagônicas na formação do professor.

A valorização do professor de Química, e de outras áreas do conhecimento, perpassa pela legitimação de seu saber e do saber fazer, para isso se faz necessário que a formação docente tenha influência sobre a prática do professor, além da realização de estudos que investiguem o processo de desenvolvimento profissional docente bem como os aspectos que interferem nesse desenvolvimento, como os obstáculos epistemológicos que discutimos.

O estudo da concepção prévia dos alunos é reconhecidamente necessário na educação de todos os níveis, entretanto, ainda não damos a devida importância para estes conhecimentos na formação de professores. A partir de estudos que investiguem o pensamento do professor, especialmente suas concepções que foram adquiridas pela vivência ambiental de forma acrítica, enquanto aluno, poderemos compreender melhor o processo de ensino e aprendizagem de professores e com isso buscarmos mudanças e melhorias na educação Química nas salas de aulas.

\section{AGRADECIMENTOS}

À Fapemat (Fundação de Amparo à Pesquisa do estado de Mato Grosso) pela bolsa de doutorado.

\section{REFERÊNCIAS}

1. Santos, W. L. P.; Schnetzler, R, P.; Educação em Química: compromisso com a cidadania, $3^{\mathrm{a}}$ ed., Unijuí: Ijuí, 2003.

2. Echeverria, A.; Mello, I. C; Gauche, R.; Educação Química no Brasil: Memórias, políticas e tendências; Rosa, M. I. P., Rossi, A. V., eds.; Átomo: Campinas, 2008. cap. 3.

3. Mortimer, E. F.; Santos, W. L. P.; Educação Química no Brasil: Memórias, políticas e tendências; Rosa, M. I. P., Rossi, A. V., eds.; Átomo: Campinas, 2008. cap. 4.

4. Milaré, T.; Richetti; G. P.; Alves-Filho, J. P.; Quim. Nova Esc. 2009, 31,3 . 
5. Auler, D.; Delizoicov, D.; Rev. Ensaio 2001, 3, 1.

6. Sasseron, L. H.; Carvalho, A. M. P.; Investigações em Ensino de Ciências 2011, 16, 1.

7. PCN+Ensino Médio: orientações Educacionais Complementares aos Parâmetros Curriculares Nacionais. MEC: Brasília, 2002.

8. Chassot, A.; Rev. Bras. Educ. 2003, 22.

9. Maldaner, O. A.; A formação inicial e continuada de professores de Química, 2a ed., Unijuí: Ijuí, 2003.

10. Mellado, V.; Revista Interuniversitaria de Formación del Profesorado 2001, 40.

11. Pena, G. B. O.; Mesquita, N. S. A.; Anais do XI Encontro Nacional de Pesquisa em Educação em Ciências, Florianópolis, Brasil, 2017.

12. Costa, K. M. G.; Forsberg, M. C. S.; Oda, W.; Latin Am. J. Sci. Educ. 2015, 1 .

13. Gatti, B.; Educação \& Sociedade 2010, 13, 31.

14. Marcelo, C.; Sísifo: Revista de Ciências da Educação 2009, 8.

15. Montero, L.; A construção do conhecimento profissional docente, Instituto Piaget: Lisboa, 2001.

16. Nóvoa, A.; Profissão Professor, 2a ed.; Porto Editora: Porto, 1995. cap. 1.

17. Guimarães, V. S.; Formação e profissão docente: cenários e propostas, PUC de Goiás: Goiânia, 2009. cap. 1.

18. Roldão, M. do C.; Rev. Bras. Educ. 2007, 12, 34.

19. Shulman, L.; Educational Researcher 1986, 15, 2.

20. Shulman, L.; Harvard Educational Review 1987, 57, 1.

21. Maldaner, O. A.; Educação Química no Brasil: Memórias, políticas e tendências; Rosa, M. I. P., Rossi, A. V., eds., Átomo: Campinas, 2008. cap. 13.

22. Fernandez, C.; Rev. Ensaio 2015, 17, 2.

23. Goes, L. F.; Dissertação de Mestrado, Universidade de São Paulo, São Paulo, 2014

24. Nezvalová, D.; Problems of Education in the 21st Century 2011, 35.

25. Talanquer, V.; Educación Química 2004, 15, 1.

26. Koballa Jr.; T. R.; Gräber, W.; Coleman, D.; Kemp, A. C.; Journal of Science Teacher Education 1999, 10, 4.
27. Fernandez, C.; Anais do VIII Encontro Nacional de Pesquisa em Educação em Ciências, Campinas, Brasil, 2017.

28. Montenegro, V. L. S.; Fernandez, C.; Rev. Ensaio 2015, 17, 1.

29. Mellado, V.; Sci. Educ. 1998, 82, 197.

30. Tardif, M.; Raymond, D.; Educação \& Sociedade 2000, 73.

31. Lopes, A. R. C.; Historia y Epistemologia de Las Ciencias 1993, 11, 3.

32. Lopes, A. R. C.; Revista Brasileira de Estudos Pedagógicos 1993, 74, 177.

33. Bachelard, G.; A formação do espírito científico: contribuição para uma psicanálise do conhecimento, Contraponto: Rio de Janeiro, 1996.

34. Lopes, A. R. C.; Quim. Nova 1992, 15, 3.

35. Lopes, A. R. C.; Currículo e Epistemologia, Unijuí: Ijuí, 2007.

36. Gomes, M. G.; Contrapontos 2002, 2, 6.

37. Porlán, R.; Martín del Pozo, R.; Rivero, A.; Harres, J.; Azcárate, P.; Pizzato, M.; Enseñanza de las Ciencias 2010, 28, 1 .

38. Porlán, R.; Rivero, A.; Martín, P.; Enseñanza de las Ciencias 1997, 15, 2.

39. Porlán, R.; Rivero, A.; Martín, P.; Enseñanza de las Ciencias 1998, 16 , 2 .

40. Lüdke, M.; André, M. E. D. A.; Pesquisa em Educação: abordagens qualitativas, E. P. U: São Paulo, 2002.

41. Moraes, R.; Galiazzi, M. C.; Análise Textual Discursiva, 2ª ed., Unijuí: Ijuí, 2013.

42. Moraes, R.; Ciência \& Educação 2003, 9, 2.

43. Pena, G. B. O.; Silveira, H. E.; Guilardi, S.; Revista Brasileira de Pesquisa em Educação em Ciências 2009, 10, 2.

44. Grillo, M.; Avaliação: uma discussão em aberto; Enricone, D., Grillo., M., eds., $2^{\mathrm{a}}$ ed., EDICUPRS: Porto Alegre, 2003, cap.1.

45. Carvalho, A. M P.; Gil-Pérez, D.; Formação de professores de ciências, 6 ${ }^{a}$ ed., Cortez: São Paulo, 1995.

46. Becker, F.; A epistemologia do professor: o cotidiano da escola, $16^{\mathrm{a}}$ ed., Vozes: Petrópolis, 2013. 